\title{
Morphological Studies on a Vitamin A-Storing Cell and its Complex with Macrophage Observed in Mouse Pancreatic Tissues following Excess Vitamin A Administration
}

\author{
By \\ Nakazo WATARI, Yasuaki HOTTA and Yoshio MABUCHI \\ The First Department of Anatomy, Nagoya City University \\ Medical School, Nagoya 467, Japan \\ -Received for Publication, December 2, 1981-
}

Key Words: Vitamin A-storing cell, Macrophage (one of mononuclear phagocytes), Mouse pancreas, Excess vitamin A administration, Phagocyte and vitamin A-storing cell complex

Summary: In this experiment, mouse pancreatic connective tissues were examined following excess vitamin $A$ administration, and a new cell type and a new cell complex were found.

In the normal state, several cell species and structures are observed in the intralobular and interlobular connective tissues such as fibroblasts, fixed macrophages (one of mononuclear phagocytes), blood capilleries with pericytes, secretory ducts, myelinated or unmyelinated nerve fibers and collagenous fibers. On the other hand, following hypervitaminosis, a special cell type occurred, thatis, a lipid-storing cell. Its lipid droplets might contain vitamin $A$ : This cell is quite similar to the fat-storing cell (Ito's cell) in the liver or vitamin A-storing cell in other tissues, and its lipid droplets revealed a special vitamin $A$ fluorescence under fluorescence microscopy. Thus this cell was named as a "vitamin A-storing cell", and it may be included in the category of the vitamin A-storing cell system (Yamada and Hirosawa, 1976).

The localization of this cell is as follows: Some of them were observed randamly in the connective tissues, but others were observed at the periphery of the blood capillaries. The latter was in close contact with the endothelial cells, and surrounded with the thin film of the basal lamina.

The origins of these vitamin A-storing cells are of at least two kinds. Some may have originated from fibroblasts (vitamin A-storing cell of fibroblast type), but others derived from pericytes of the blood capillaries (vitamin A-soring cell of pericyte type).

In the connective tissues of the mouse pancreas following excess vitamin A administration, some activated macrophages were also observed to contain a number of peculiar vacuolar phagosomes, and the cell sometimes showed intimate contact with the vitamin A-storing cell, especially the fibroblast type. The macrophage and vitamin A-storing cell formed a complex, which the authors tentatively named a "phagocyte and vitamin A-storing cell complex". The significances of the vitamin A-storing cells and the complex is also discussed. 
Vitamin $\mathrm{A}$ is one of the most important active substances in animals including man, so that it is constantly stored in certain tissues such as the liver. However, excess vitamin A has a toxic action for animals (Pinkerton, 1961), and so vitamin $\mathrm{A}$ is usually stored in special cell types. Nakane (1963) first confirmed with fluorescence microscope that the fat-storing cell of Ito $(1969,1978,1980)$ in the liver is one of the special vitamin A-storing cells, whose lipid droplets contain essentially vitamin A. Recently, similar vitamin A-storing cells have been discovered by certain researchers using radioautographic or some other histological methods in certain organs or tissues including lung, trachea, stomach, intestine, spleen, lymph nodes, adrenal gland, urinary bladder, uterus, ovarian tubes, renal medulla, red bone marrow, thymus and dermis of the skin (Hirosawa, Yamada and Omura, 1974 ; Yamada and Hirosawa, 1976; Hirosawa and Yamada, 1977, 1978, 1980 ; Inouye, Minick and Kent, 1977; Yorifuji, Hirosawa and Yamada, 1980; Kusumoto and Fujita, 1977 ; Yamamoto, Enzan, Hara and Iijima, 1978).

Kusumoto and Fujita (1977) have suggested that vitamin A-storing cells might be distributed widely in the whole body including the above-mentioned tissues. And Yamada and his coworkers (Yamada and Hirosawa, 1976; Hirosawa, 1977; Hirosawa, 1977 ; Yorifuji, 1981) have postulated a vitamin A-storing cell system which includes the total vitamin A-storing cells observed in certain organs or tissues already mentioned above. However, no one has observed such vitamin A-storing cells in the pancreatic tissues to date. The present authors observed the lipid-storing cells in the mouse pancreatic tissues during tissue study following excess vitamin A administration (Watari, et al., 1972). These lipid-storing cells are very similar to the vitamin A- storing cells observed in other tissues so we would like to re-examine the mouse pancreatic tissues to determine whether such vitamin A-storing cells exist. Also, we would like to ascertain whether is a special cell complex in them (e.g., a phagocyte and fat-storing cell complex, which we observed recently in the liver of certain animals including man, in both normal and some experimental conditions, Watari, et al., 1980; Watari, 1980, 1981).

\section{Materials and Methods}

Fifteen DDY-strain mice were used in this experiment. Five mice were kept in an air-conditioned room without any treatment. Ten mice were injected intramuscularly with vitamin A (Retinol palmitate; Chocola A, Eizai Co., Ltd, Tokyo) at 5,000 IU every day for 14 days. The animals were sacrificed at day 15 , and the pancreatic tissues were fixed with a mixture of $2.5 \%$ glutaraldehyde and $1 \%$ osmic acid for 2 hours at $4^{\circ} \mathrm{C}$. The tissues were embedded in Epon 812 after dehydration with ethanol and propylene oxide, and then cut into ultrathin sections of about $100 \mathrm{~nm}$ thick for electron microscopical observations. Some tissues were fixed with $10 \%$ neutralized formalin, cut into frozen sections and observed by a fluorescence microscope to ascertain the existence of vitamin A within the lipid droplets in the lipid-storing cells. Under the ultraviolet light (excited by $328 \mathrm{~m} \mu$ ), vitamin $\mathrm{A}$ has been identified as a special fluorescence of green color (Fig. 1), and its fluorescence faded away within seconds (Fig. 2: Popper and Greenberg, 1941; Popper, 1944 ; Kusumoto and Fujita, 1977 ; Yamamoto, et al., 1978).

\section{Mouse pancreatic connective tissues in the normal state \\ In the intralobular and interlobular con- nective tissues of the mouse pancreas in}


the normal state, there are some regular cell elements and structures such as secretory ducts, blood capillaries (Figs. 5, $6,8,10$ ) and vessels, myelinated or unmyelinated nerve fibers and collagenous fibers along with a few free cells including fibroblasts (Fig. 3) and fixed macrophages (Fig. 4). In the normal state, macrophages and fibroblasts are not so easily distinguished, because their fine structures are quite similar, except for some typical structures; the quiescent fibroblasts by electron microscopy are characterized by a small Golgi apparatus and only a few cisternae of rough-surfaced endoplasmic reticulum. The mitochondria are long and slender. On the other hand, the fixed macrophages, one of mononuclear phagocytes, have nuclei which tend to be somewhat smaller and more darkly stained than those of fibroblasts. The Golgi apparatus is small, and the mitochondria are short rods, and the cytoplasm is more heterogenous than that of fibroblasts, often containing a variety of lysosomal granules and small vacuoles (Fig. 4). However, such typical fibroblasts and macrophages were not so frequently observed in the present experiment in the control animals (see Figs. 3, 4).

Pericytes were also observed in the mouse pancreatic tissues, whose cytoplasm elongated along the neighboring endothelial cells of the blood capillaries, and they were surrounded by a thin basal lamina (Fig. 5). The blood capaillary with pericyte was sometimes observed like a ring-stone when cut transversally at the nuclear portion (Fig. 5). The cytoplasm of the pericyte usually had undeveloped cell organelles, except for a number of small vesicles, a majority of which might have originated from pinocytotic vesicles (Fig. 5).
II. Mouse pancreas following administration of excess vitamin $A$

Following the excess vitamin A administration, very peculiar morphological alterations were in the intralobular and interlobular connective tissues as follows:

(1) Vitamin A-storing cells: A special cell type was found in the connective tissues, which contained several lipid droplets within the cytoplasm (Figs. 6, 7, $8,9,10,12$ ), and also had a relatively well-developed rough-surfaced endoplasmic reticulum (Figs. 6, 8, 9, 13, 14). Some of the latter were dilated and contained amorphous substance within (Figs. 13, 14). These cells also contained a small Golgi apparatus (Fig. 8) and a number of free ribosomes. Some such cells had autophagic vacuoles containing electron-dense substance or crystalline structures within (Figs. 13, 14). This cell type is quite similar to the fat-storing cell within the liver or vitamin A-storing cell in certain other organ tissues. By fluorescence: microscopy, the lipid droplets in the cells displayed a weak fluorescence of green color (Fig. 1), suggesting the presence of vitamin A within the lipid droplets just like the fat-storing cell in the liver or vitamin A-storing cells in certain other tissues (see Kusumoto and Fujita, 1977 ;: Yamamoto, et al., 1978).

The localization and shapes of the: vitamin A-storing cells were as follows: (a) Fibroblast type; some were found randomly in the connective tissues, not only in the pancreatic exocrine parts (Figs. 6, 7, 12, 13), but also in the endocrine parts (Fig. 8). The cell shapes were variable; some were oval in shape with a rounded or oval nucleus without any visible cytoplasmic projections (Fig. 8), while others were star-shaped with many cytoplasmic projections (Fig. 13) or elongated and striated with a long nucleus (Figs. 6, 7). These cells are quite similar to the normal fibroblasts in their con- 
figuration and localization. Some vitamin A-storing cells were surrounded by collagenous fibers (Figs. 7, 13). (b) Pericyte type; most vitamin A-storing cells were located around the endothelial cells of the blood capillaries within the connective tissues, that is, the cells firmly adhered to the endothelial cells with their attenuated cytoplasm, and the whole cell body was usually surrounded by a thin basal lamina which belongs to the endothelial cells (Figs. 9, 10). In other words, the cell was embedded in the basal lamina of the blood capillary. Some such vitamin A-storing cells contained a bundle of thin filaments along their attenuated cytoplasm, and also contained a number of pinocytotic vesicles, just like the endothelial cells (Fig. 10). These cells are equivalent to the pericytes of the blood capillaries in their localization (compare Fig. 5 with Fig. 9). When the blood capillary was cut transversally, the pericyte or vitamin Astoring cells of pericyte type evidenced a ring-stone shape (see Fig. 5).

(2) Wandering cells

There were at least two kinds of wandering cells within the connective tissues. The first was eosinophilic leucocyte containing special crystalline granules (Fig. 11). The second was a mononuclear phagocyte (macrophage), which contained a number of phagosomes (Figs. 11, 12, 13, 14). A majority of the phagosomes had vacuolar structures containing an electrondense eccentric core (Figs. 11, 12, 13, 14). The shape of the phagocytes was irregular and sometimes contained one eccentric nucleus (Fig. 11). Some such cells loosely contacted the endothelial cells of the blood capillaries or exocrine cells (Figs. 11, 12), but others were unattached in the intralobular or interlobular connective tissues.

(3) The intermediate cell between the pericyte type of vitamin A-storing cell and fibroblast type of vitamin A-storing cell was rarely observed, which loosely contacted with the endothelial cells of the blood capillary, and was partly surrounded by a basal lamina.

(4) Some phagocytes were observed to have intimate contact with the vitamin A-storing cell, especially with the fibroblast type one. The conbination was tentatively named a "phagocyte and vitamin A-storing cell complex." However, there was no any conjoining apparatus between them, suggesting a possible temporary connection (Figs. 12, 13, 14).

\section{Discussion}

Following 2 weeks of excess vitamin A administration very peculiar morphological changes occurred in the mouse pancreas. Lipid-storing cells occurred very frequently within the intralobular and interlobular connective tissues, not only in the exocrine parts but also in the endocrine parts (Figs. 6, 7, 8, 9, 10, 13, 14). They were quite possibly vitamin A-storing cells, because they were very similar to the fat-storing cell of Ito (1969, 1978, 1980) containing vitamin A within its fat or lipid droplets. Moreover, the lipidstoring cells in the present experiment revealed a special vitamin A fluorescence under fluorescence microscopy within their lipid droplets (Fig. 1) suggesting that they contain vitamin A exactly.

Recently, Yamada and Hirosawa (1976, 1977, 1978, 1980) and other researchers (Hirosawa, Yamada and Omura, 1974; Inouye, Minick and Kent, 1977 ; Yorifuji, Hirosawa and Yamada, 1980; Kusumoto, and Fujita, 1977 ; Yamamoto, et al., 1978) have reported the vitamin A-storing cells following the excess vitamin A administration in mice or rats, in other than liver tissues (i.e., lung, trachea, stomach, intestine, spleen, lymph nodes, adrenal gland, urinary bladder, uterus, ovarian tubes, kidney, red bone marrow, thymus 
and dermis of the skin). These vitamin A-storing cells were also quite similar to the lipid-storing cells observed in the present experiment.

Following hypervitaminosis A free mononuclear phagocytes (free macrophages) were also observed frequently in the mouse pancreas, which were characterized by special vacuolar phagosomes. These phagosomal vacuoles contained electron-dense cores within (Figs. 11, 12, 13, 14). Other cytoplasmic inclusions were as follows: a few mitochondria, free ribosomes and a number of irregular vesicles (Figs. 11, 12, 13, 14). Similar phagocytes were also observed by the authors in the liver of certain animals following vitamin $\mathrm{A}$ or $\mathrm{E}$ excess administration (Watari, 1980, 1981; Watari, et al., 1980).

In the mouse pancreatic tissues in the present experiment, these two cells, such as vitamin A-storing cell and free macrophage sometimes made intimate contact with each other to form a complex, suggesting cooperation. We have reported a similar cell complex in the liver of certain animals including man, which we named a "phagocyte and fat-storing cell complex" (Watari, 1980, 1981; Watari, et al., 1980), speculating that these cells in the complexes might cooperate mutually. Thus the phagocyte (macrophage) is at first activated in some pathological conditions such as inflammation or intoxication including excess vitamin A administration. The result is phagocytosis of toxic or foreign substances including antigenic proteins, whose infor mation may be directed to the fat-storing cell through the complex's cytoplasmic connection. Then the fat-storing cell might elaborate certain substances such as immunological one. The fat-storing cells in the liver have an well-developed rough-surfaced endoplasmic reticulum, which sometimes dilated and contained some electrondense substances suggesting that it might elaborate such immunological or other substances, similar to the plasma cell elaboration of immunological substance (see Bloom and Fawcett, 1975). In this experiment, such cooperation was postulated in the phagocyte and vitamin A-storing cell complex, although further experiments will be needed to clarify this function exactly.

The origin of the vitamin A-storing cells in this experiment is thought to be of at least two kinds; one is the fibroblast, and the other is pericyte of the blood capillary, so that vitamin A-storing cells originated from fibroblasts are distributed freely in the intralobular and interlobular connective tissues of the pancreatic tissues, not only in the exocrine parts. (Figs ${ }^{\circ} 6,7,12$, $13,14)$ but also in the endocrine parts (Fig. 8). On the other hand, vitamin Astoring cells originating from the pericytes firmly adhered to the endothelial cells and were surrounded by a thin basal lamina (Figs. 9, 10). These two cells are also observed in the mouse pancreatic connective tissues under normal conditions (the original types, namely fibroblasts and pericytes). However, the two cells do not have any lipid droplets during the normal state (Fig. 3), so it is speculated that they only have an emergency vitamin A-storage capability, which protects from toxication such as excess vitamin A. The autophagic vacuoles containing crystalline structures within the vitamin A-storing cells might be partly responsible for this protection against such toxicity (Watari, 1973).

\section{Acknowledgments}

This experiment was supported by a Grant-in-Aid for Scientific Research from the Ministry of Education, Science and Culture of Japan, and also a Grant from the Ojinkai in Nagoya City University Medical School, Nagoya, Japan. 


\section{References}

1) Bloom, W., and D. W. Fawcett: A Textbook of Histogy (ed. by W. Bloom and D. W. Fawcett), 10th Edition, W. B. Saunders Co., Philadelphia, London, Toronto, 1975.

2) Hirosawa, K.: Vitamin A-storing cell system (Japanese review). The Metabolism, 14 : 1861-1868, 1977.

3) Hirosawa, K., and E. Yamada: An autoradiographic study of vitamin. Astoring cells in mouse spleen (English abstract). J. Electron Microsc., 26 (3) : 270-271, 1977.

4) Hirosawa, K., and E. Yamada: Localization of vitamin A-storing cells in the mouse adrenal gland: An electron microscopic autoradiographic study. Am. J. Anat., 153: 233-250, 1978.

5) Hirosawa, K., and E. Yamada: Vitamin A-storing cells in the lymph nodes of mouse (Japanese abstract). Acta Anat. Nippon., 55 (4) : 446-447, 1980.

6) Hirosawa, K., E. Yamada and Y. Omura : Localization of ${ }^{3} \mathrm{H}$-vitamin $\mathrm{A}$ in the mouse lung as revealed by electron microscope radioautography (Japanese abstract). Acta Anat. Nippon., 49 (1) : 60, 1974.

7) Inouye, T., T. Minick and G. Kent: Vitamin A-storing cells in the kidney and their fibrogenic potential (English abstract). J. Cell Biol., 75: 192a, 1980.

8) Ito, T.: Fine structure of the sinusoidal wall of the liver. A review (Japanese text). Kitakanto Igaku, 19: 429-474, 1969.

9) Ito, T.: Structure and function of the fat-storing cell (FSC) in the liver. A review (Abstract in English). Acta Anat. Nippon., 53 : 393-422, 1978.

10) Ito, T.: Fat-storing cell in the liver. Morphology and function. The Cell (Japanese Journal), 12 (5) : 176-187, 1980.

11) Kusumoto, Y., and T. Fujita: Vitamin A uptake cells distributed in the liver and other organs of the rat. Arch. histol. jap., 40 (4) : 121-136, 1977.

12) Nakane, P. K.: Ito's "fat-storing cell" of the mouse liver (English abstract). Anat. Rec., 145: 265-266, 1963.

13) Pinkerton, H.: Chapter 17. Vitamins and deficiency diseases; In; Pathology (ed. by W. A. D. Anderson), 4th Edition, C. V. Mosby Co., P. 425, 1961.

14) Popper, H.: Distribution of vitamin A in tissue as visualized by fluorescence microscopy. Physiol. Rev., 24 : 205-224, 1944.

15) Popper, H., and R. Greenberg: Visualization of vitamin $A$ in rat organs by fluorescence microscopy. Arch. Pathol., 32: 11-32, 1941.

16) Yamada, E., and K. Hirosawa: The possible existence of a vitamin A-storing cell system. Cell Struct. Funct., 1: 201-204, 1976.

17) Yamamoto, M., H. Enzan, H. Hara and S. Iijima: Fluorescence and electron microscopic studies on the perivascular mesenchymal cells and fibroblasts after vitamin A administration. Acta Path. Jap., 28 (4) : 513-521, 1978.

18) Yorifuji, H.: Vitamin A-storing cells (Japanese review). The Metabolism, 18 (5) : 415-424, 1981.

19) Yorifuji, H., K. Hirosawa and E. Yamada : Vitamin A-storing cell in mouse urinary bladder. An autoradiographic study (English abstract). J. Electron Microsc., 29 (3) : 288, 1980.

20) Watari, N.: Ultrastructural alterations of the mouse liver after the prolonged administration of BHC (Abstract in English). J. Clin. Electron Microsc., 5 (4) : 1449-1456, 1973.

21) Watari, N.: Fine structural analysis of a "phagocyte-fat-storing cell complex" in the liver (I). In; Abstracts of the 11th Internat. Congr. of Anatomists (Aug. 17-23, 1980, Mexico City), p. 26, 1980.

22) Watari, N.: Phagocyte and fat-storing cell complex in the liver (Japanese review). Igaku no Ayumi, 119 (2): appendix, 1981.

23) Watari, N., Y. Hotta, Y. Mabuchi, M. Kanai and Y. Kurono: Ultrastructural observations of Kupffer cells and other liver sinusoidal and perisinusoidal cells, with special reference to a "phagocyte- 
fat-storing cell complex" (English abstract). Acta Anat. Nippon., 55 (2) : 259-260, 1980.

24) Watari, N., K. Torizawa, A. Saeki and K. Takada: Ultrastructural alterations of the mouse pancreas after the prolonged and overdose administration of vitamin A (Abstract in English). J. Electron Microsc., 21 (1) : 40-45, 1972. 


\section{Explanation of Figures}

\section{Plate I}

Fig. 1. Vitamin A-storing cells in the mouse pancreatic exocrine (EX) and endocrine (I) parts following excess vitamin A administration demonstrated by fluorescence microscopy. Arrows indicate the fluorescent cells which may contain vitamin A within the lipid droplets. $\times 700$.

Fig. 2. Seconds after excitation by ultraviolet light, the fluorescent color almost disappears in the same area observed in the prvious figure (compare with Fig. 1). $\times 700$. 
Plate I
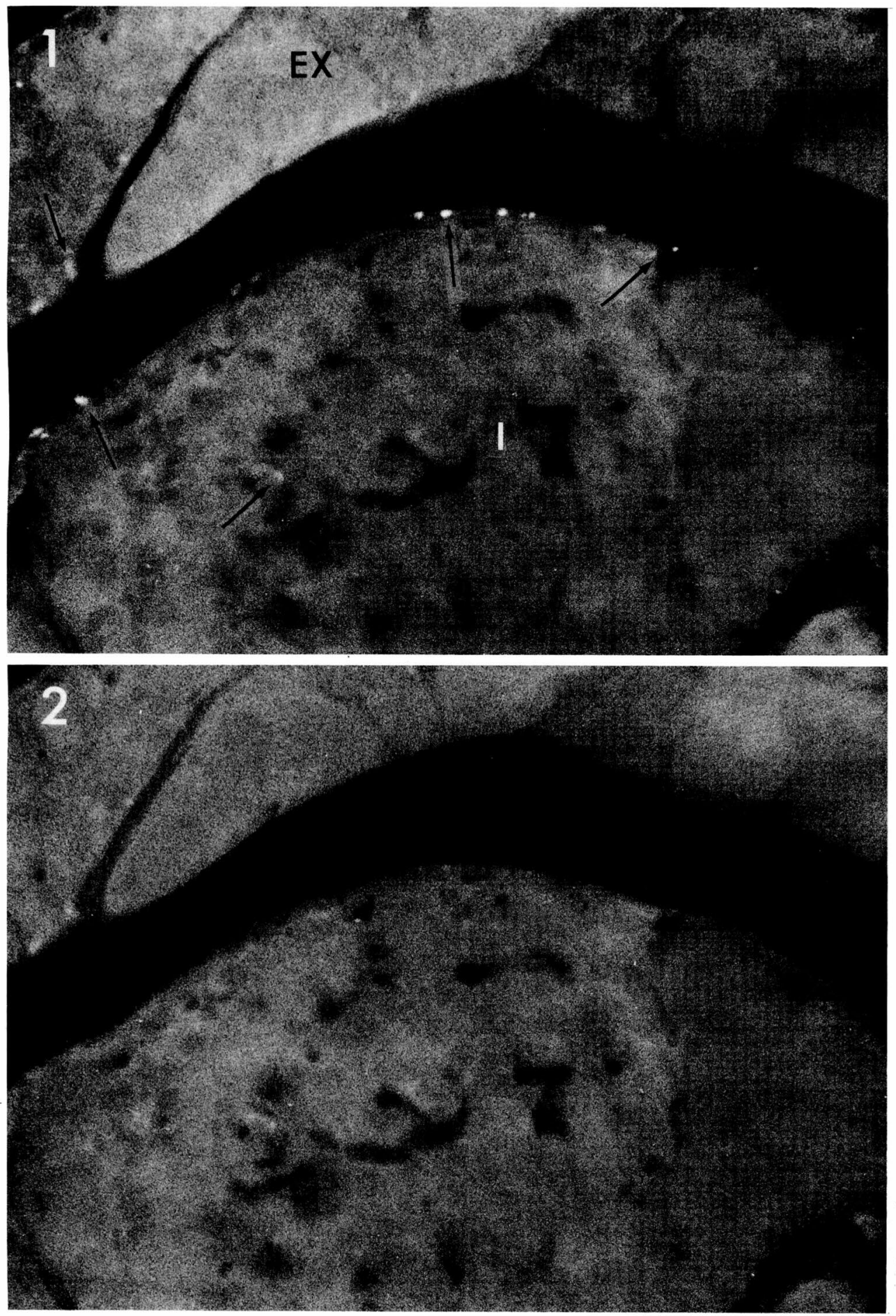

N. Watari, et al. 


\section{Plate II}

Fig. 3. An undeveloped fibroblast (U) is observed along the endothelial cells of the blood capillary (V) in the interlobular connective tissue of the normal mouse pancreas. The cell has cytoplasmic projections, and contains relatively clear cytoplasm, in which a few mitochondria, vacuoles and free ribosomes are observed. EX; exocrine cells. $\times 10,000$.

Fig. 4. This cell may be a fixed macrophage containing a large number of vesicules and tubules, and some vacuoles along with heterogenous bodies, from the normal mouse pancreas. EX; acinar cells. $\times 23,000$, 
Plate II
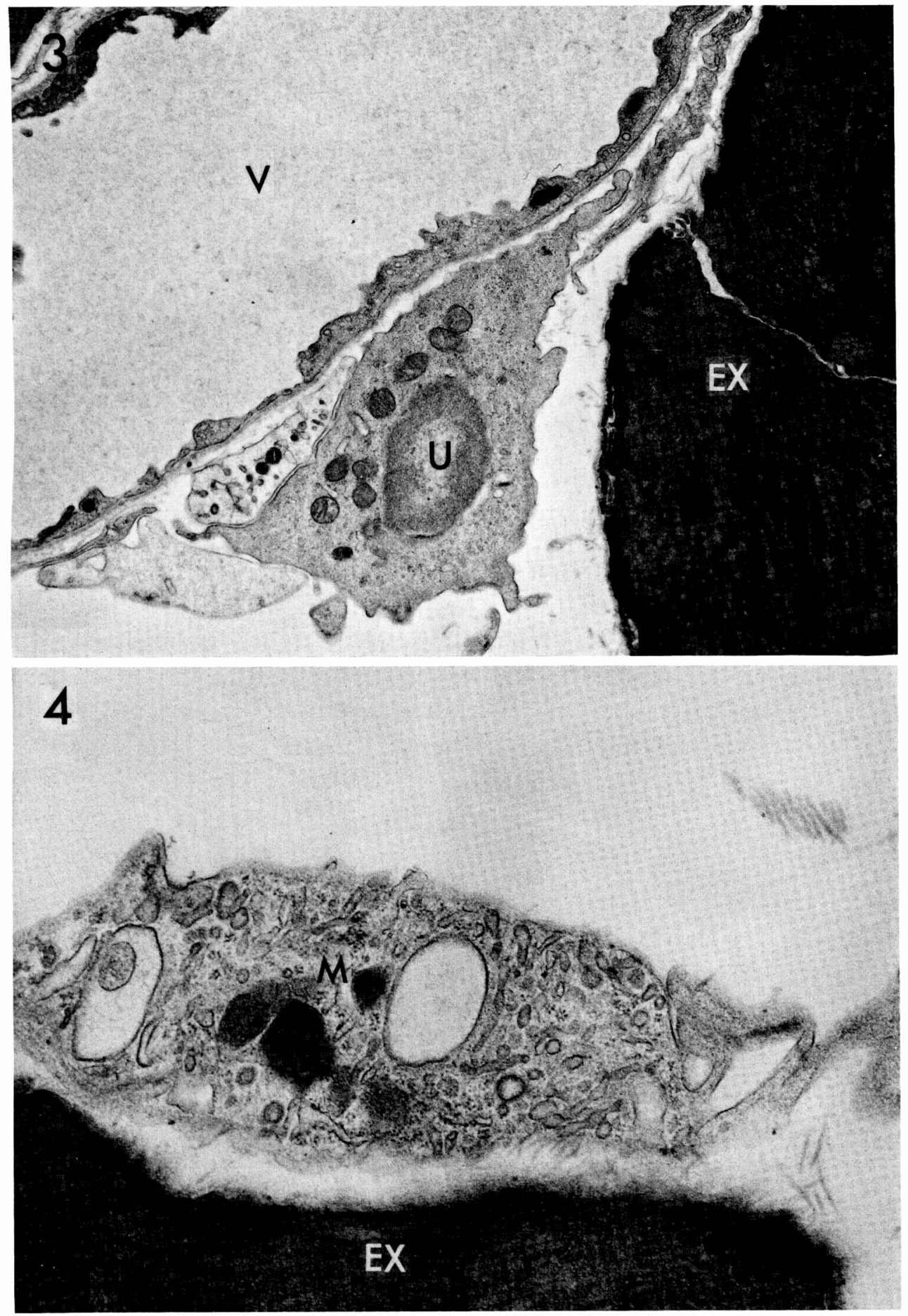

N. Watari, et al. 


\section{Plate III}

Fig. 5. A small capillary (V) with a pericyte $(\mathrm{P})$ is cut transversally, so that a ring-stone shape is observed. The pericyte is surrounded by a thin layer of basal lamina (arrows). Following the excess administration of vitamin A. In this case, the pericyte does not have lipid droplets. I; islet cell. $\times 10,000$.

Fig. 6. One fibroblast type of vitamin A-storing cell (A) observed between the blood capillaries (V) and the pancreatic acini (EX). The lipid droplets are located bipolarly (arrows). Following excess vitamin A administration. $\times 5,000$. 


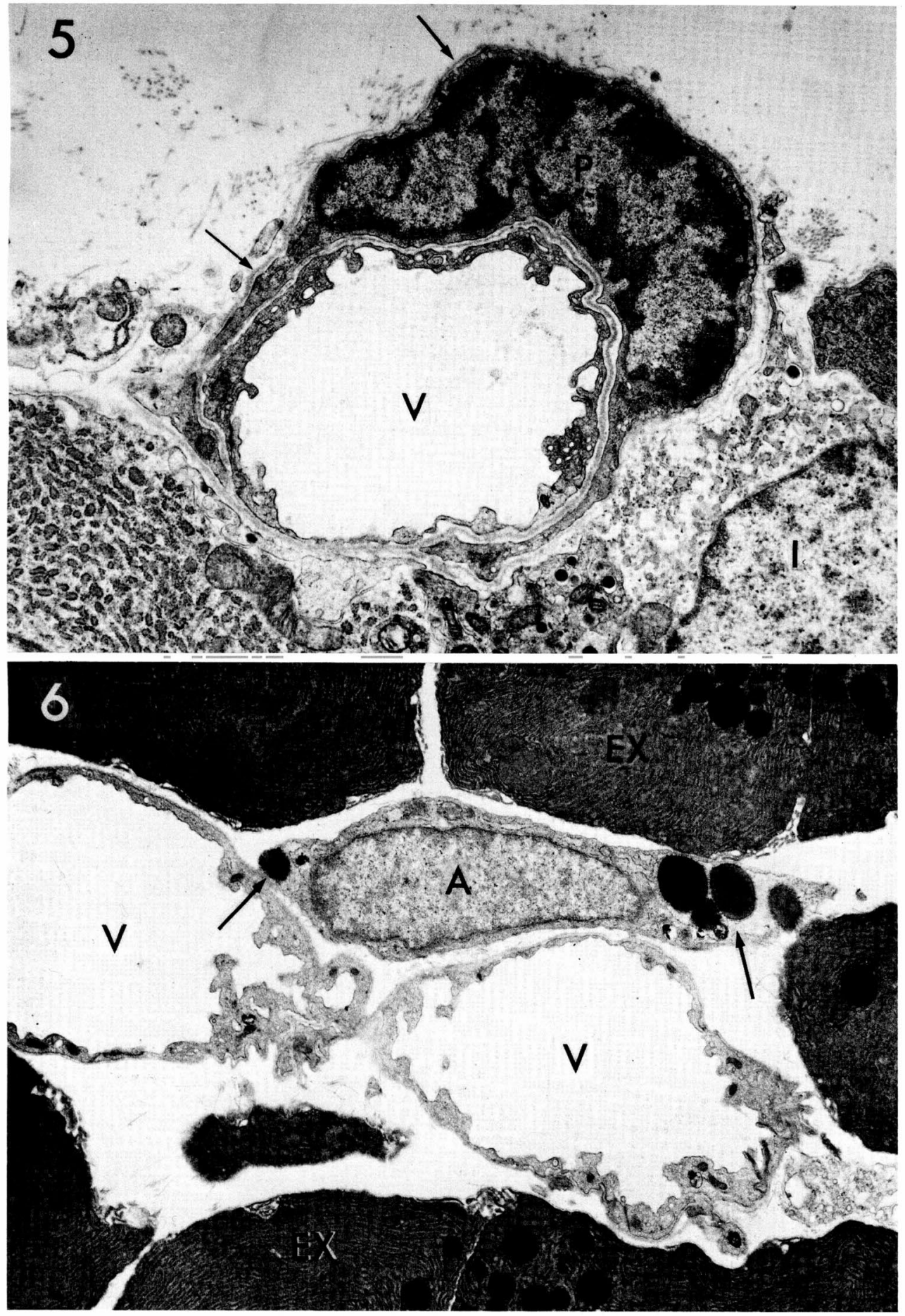

N. Watari, et al. 


\section{Plate IV}

Fig. 7. A fibroblast type of vitamin A-storing cell (A), which is irregularly elongated, and contains an elongated nucleus and lipid droplets (arrows). This cell is embedded in bundles of collagenous fibers (F). D; secretory duct, EX; exocrine cells. Following excess administration of vitamin A. $\times 7,000$.

Fig. 8. Among the pancreatic islet tissue, a vitamin A-storing cell is observed to contain two nuclei $(\mathrm{N})$ and one lipid droplet $(\mathrm{L})$. The cell is in close contact with the islet B-cells (B), but there are some connective tissues between the vitamin A-storing cell and the blood capillary (V) suggesting that this cell type may belong to the fibroblast type. An arrow indicates Golgi apparatus. $\times 9,000$. 


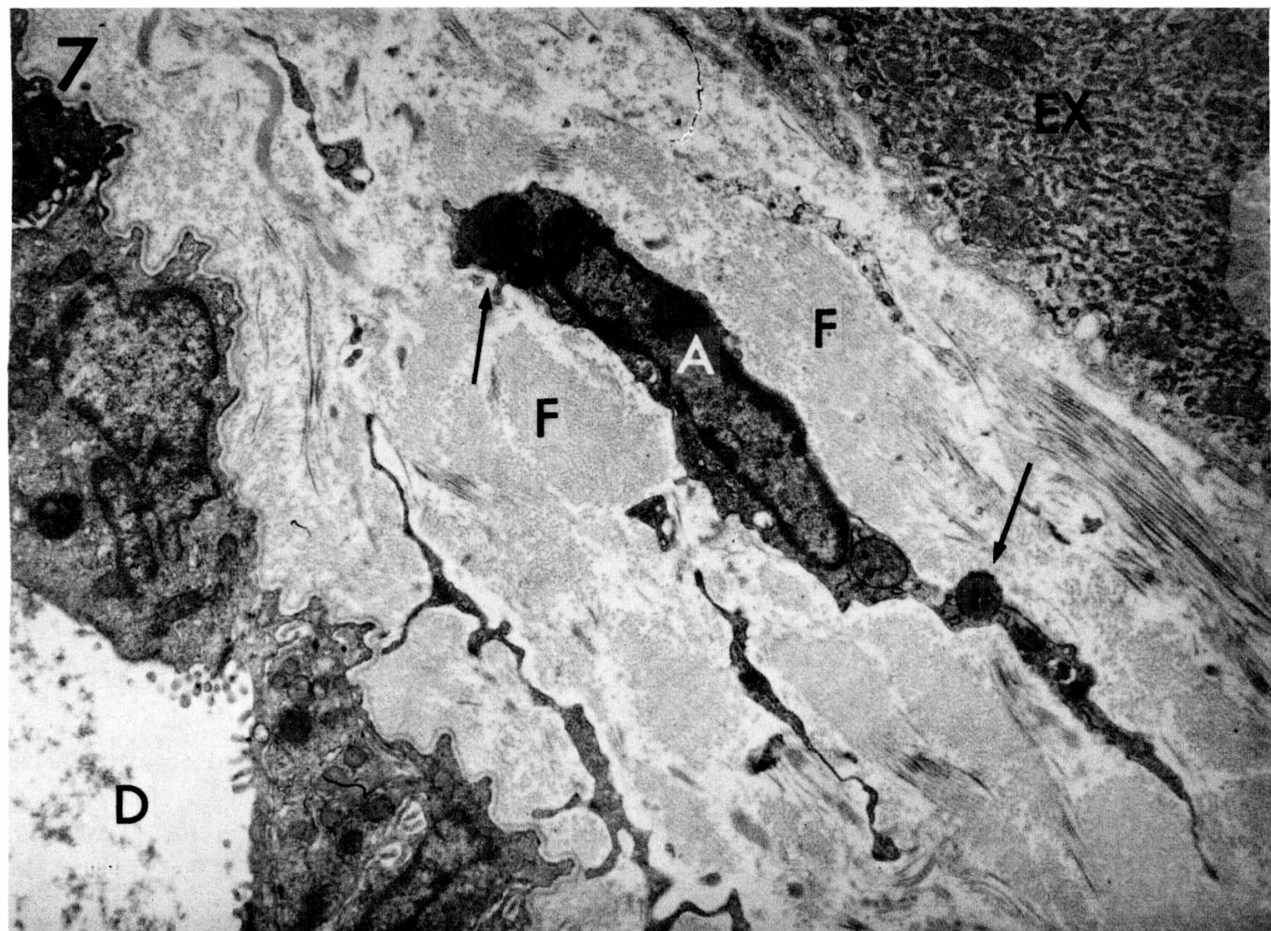

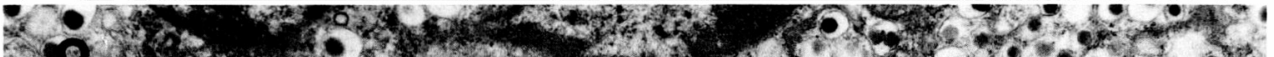

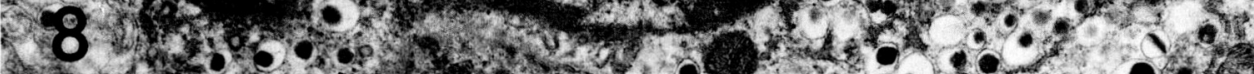

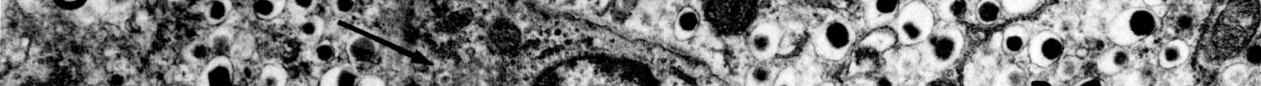

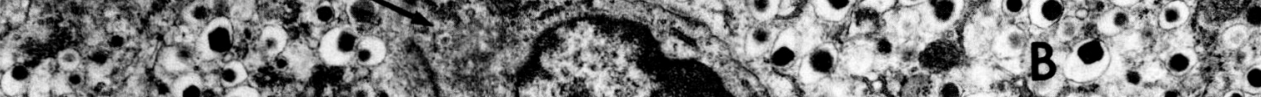

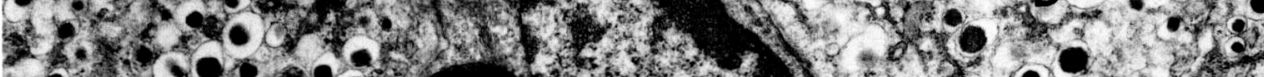

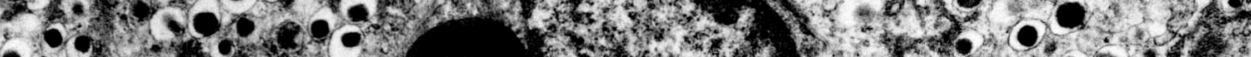
8.6.

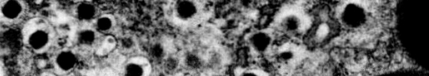

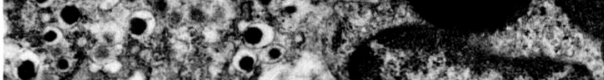

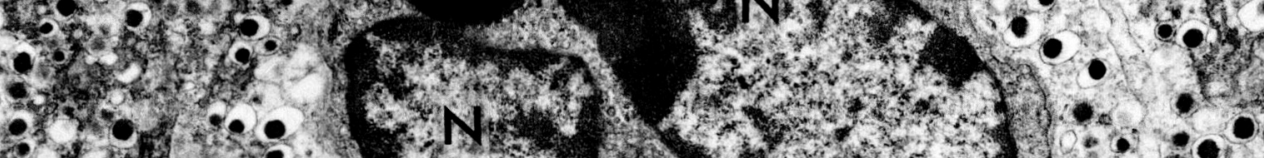

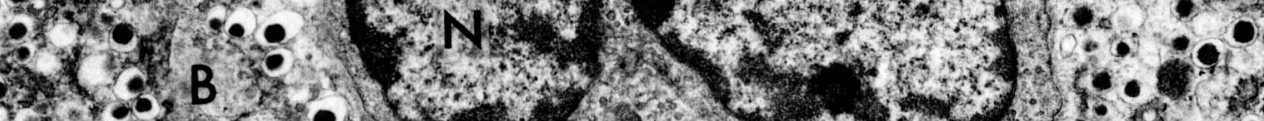

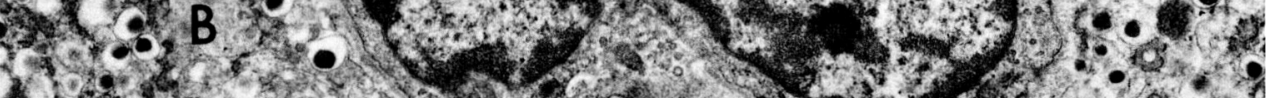

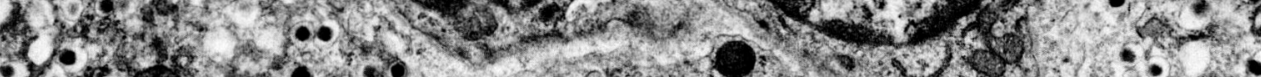

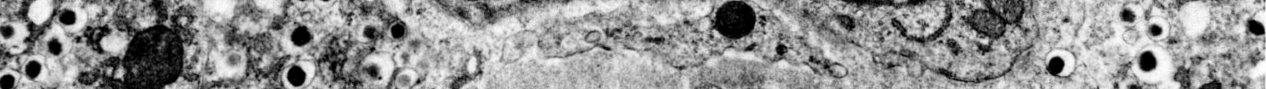

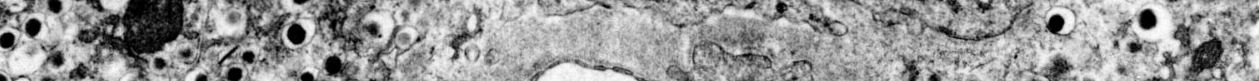

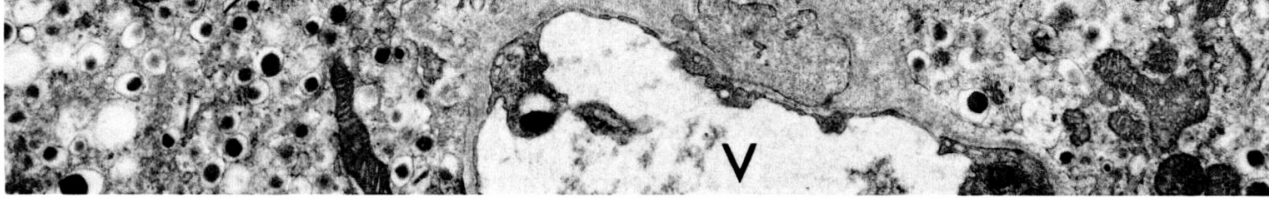

N. Watari, et al. 


\section{Plate V}

Fig. 9. A typical vitamin A-storing cell, observed at the periphery of the blood capillary (V), contains only one large lipid droplet (L). The nucleus $(\mathrm{N})$ is distorted by its lipid droplet. The whole cell body is surrounded by the basal lamina of the blood capillary (arrow), suggesting that the cell may have originated from the pericyte. Following excess vitamin A administration. Ex; exocrine cell $\times 13,000$.

Fi8. 10. This vitamin A-storing cell is also a pericyte type, which is surround ed by thin basal lamina, and contains two lipid droplets (L) showing a beaded structure. The cell also contains a number of pinocytotic vesicles and filamentous structures (arrow). V; blood capillary lumen, E; endothelial cells, EX; exocrine cells. $\times 8,000$, 


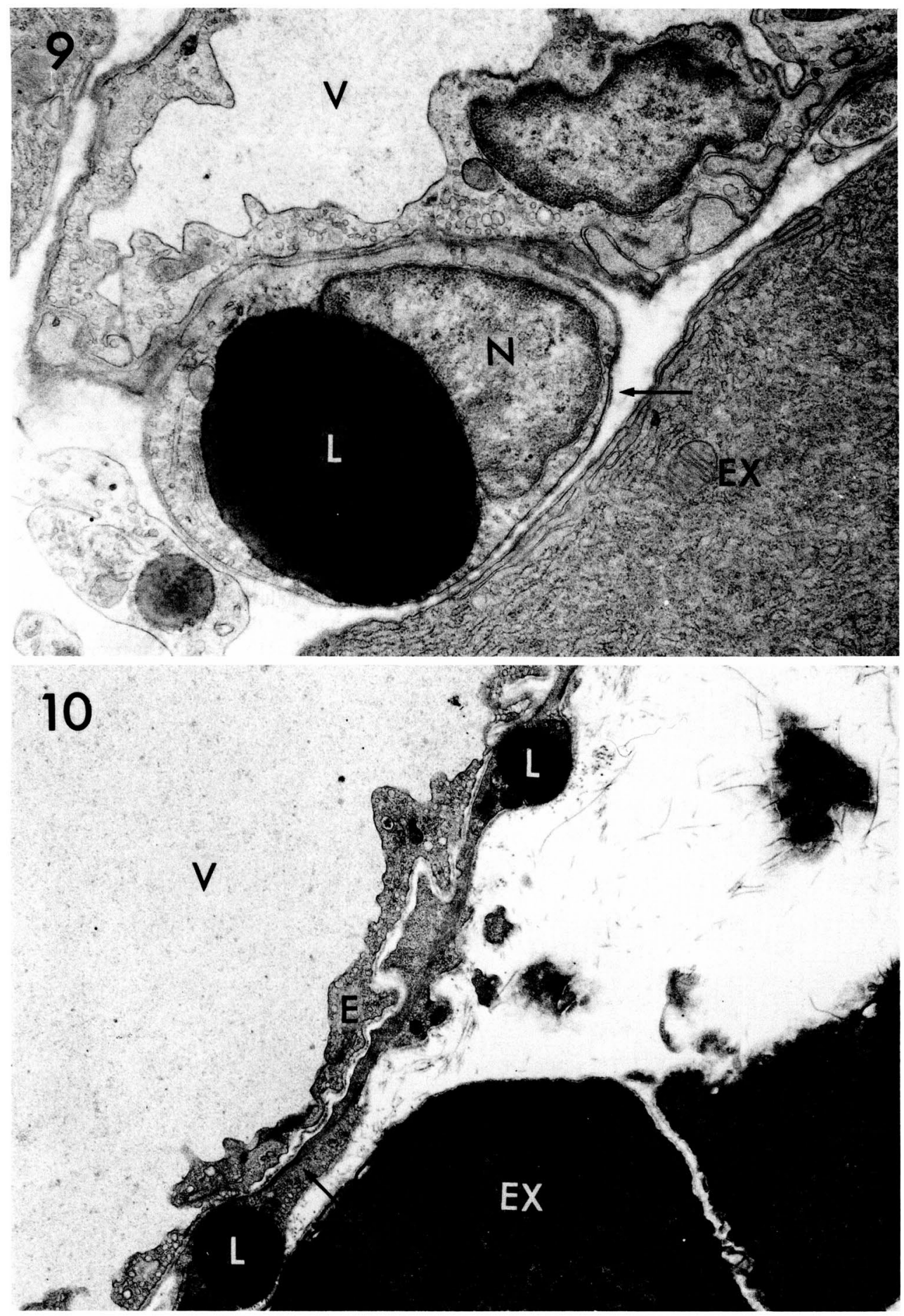

N. Watari, et al. 


\section{Plate VI}

Fig. 11. Macrophage (M) and eosinophilic leucocyte (EL) are observed in the interlobular connective tissue of the mouse pancreas following excess vitamin A administration. The macrophage has peculiar vacuolar phagosomes with eccentric cores, vacuoles and small vesicles. On the other hand, the eosinophilic leucocyte has a lobulated nucleus $(\mathrm{N})$ and typical special granules. Both cells are located separately close to the exocrine cells (E $\mathrm{X}) . \quad \times 7,000$.

Fig. 12. A phagocyte (macrophage; M) and vitamin A-storing cell (A) complex is observed in the intralobular connetive tissue of the mouse pancreas following the excess vitamin A administration. The phagocyte (macrophage) has a number of peculiar vacuolar phagosomes, and the vitamin A-storing cells contain lipid droplets (L). EX; exocrine cells. $\times$ 8,000 . 
Plate VI
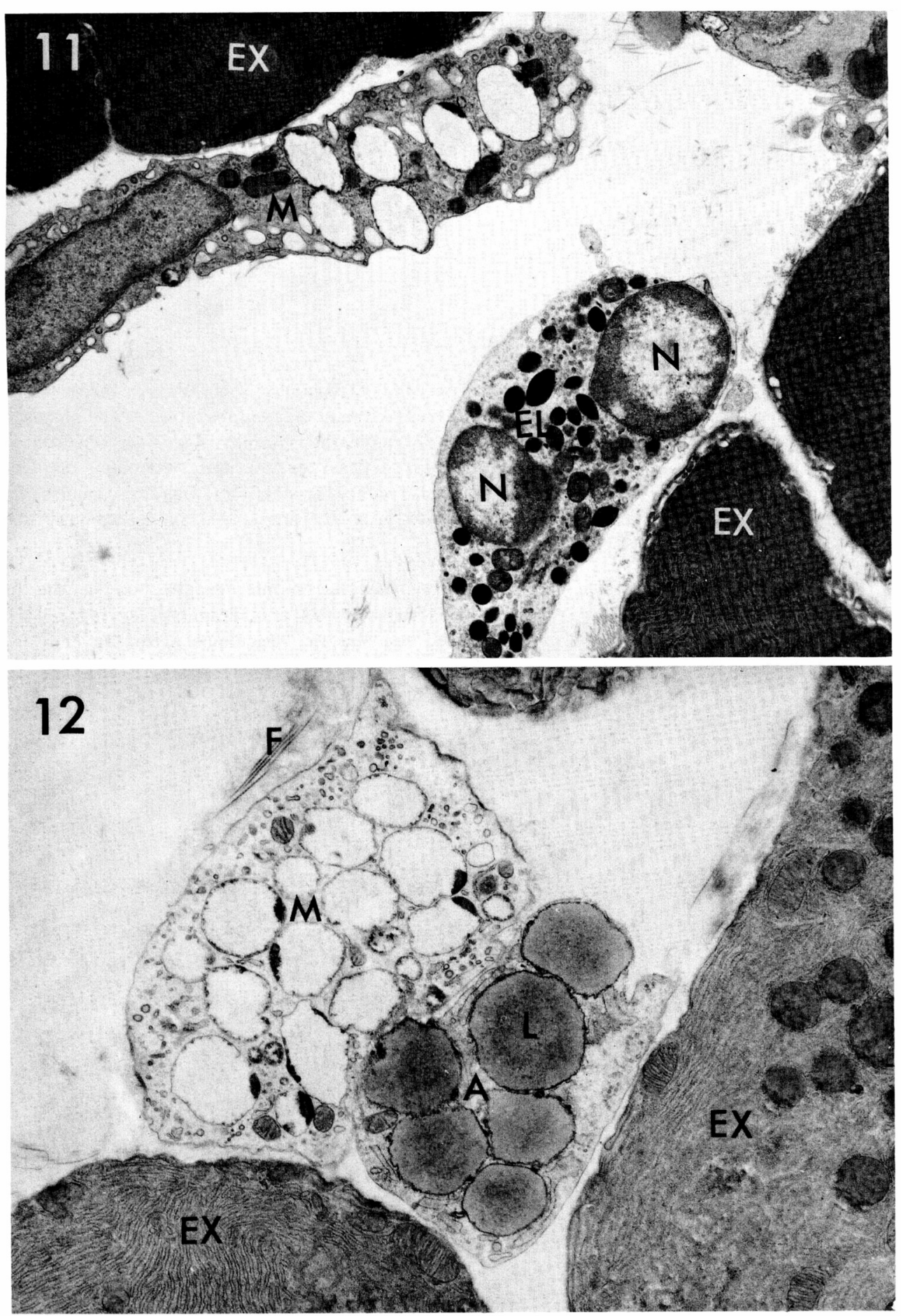

N. Watari, et al. 


\section{Plate VII}

Fig. 13. A phagocyte (M) and vitamin A-storing cell (A) complex is observed in the pancreatic connective tissue of the mouse following excess vitamin A administration. The phagocyte (M) contains typical vacuolar phagosomes, although the vitamin A-storing cell contains lipid droplets (L), dilated cisternae of rough-surfaced endoplasmic reticulum (arrow-1) and a number of free ribosomes. The cell also contains small autophagic vacuoles with crystalline structures (arrow-2). The complex is partly surrounded by collagenous fibers (F). EX; exocrine cells, V; blood capillary. $\times 8,000$.

Fig. 14. Higher magnification of a part of the previous electron micrograph showing the intimate connection (arrow-1) of both cells, macrophage (M) and vitamin A-storing cell (A). Arrow-2; dilated cisternae of rough-surfaced endoplasmic reticulum, arrow-3; crystalline structures in the autophagic vacuole. L; lipid droplets. $\times 19,000$. 


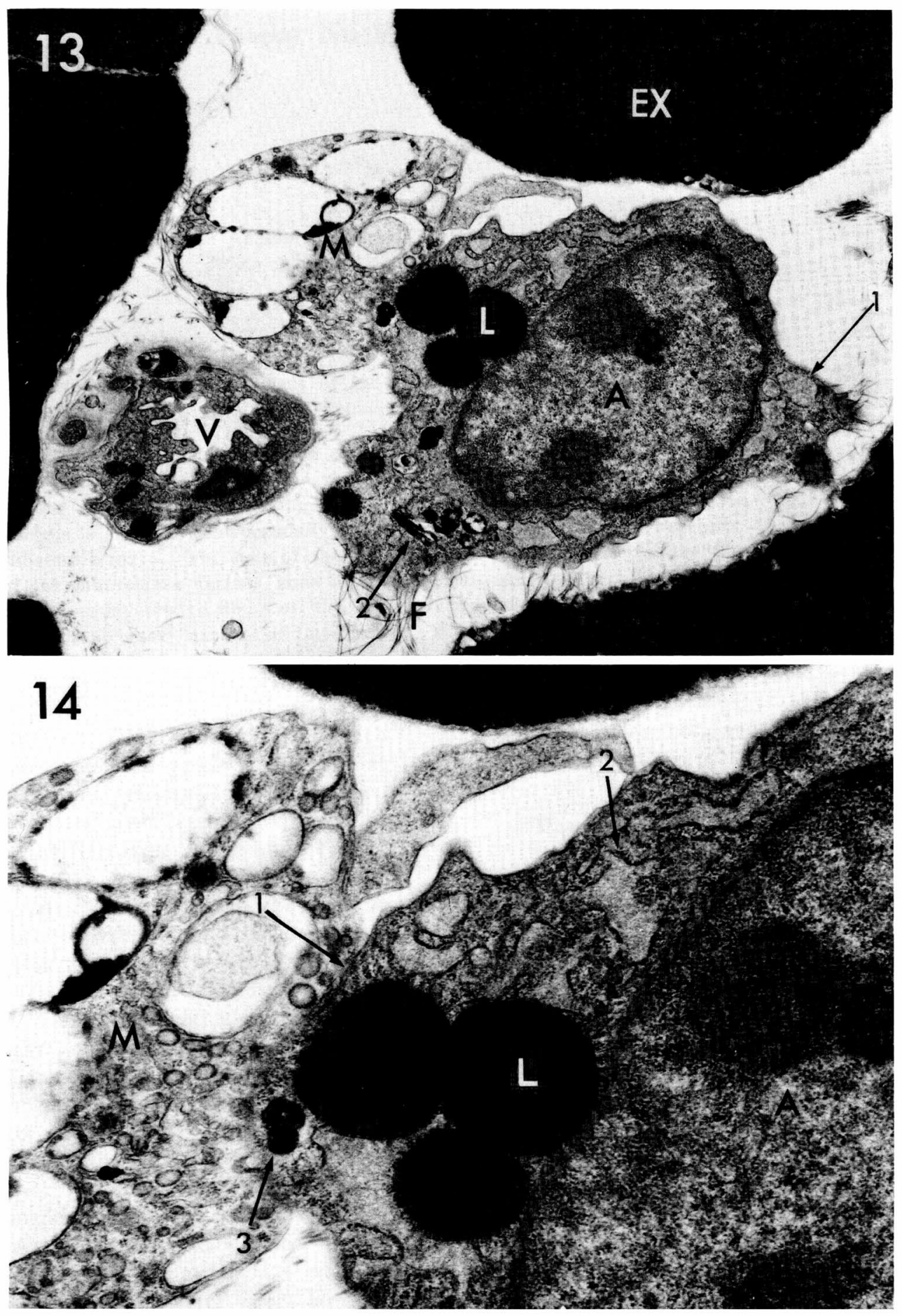

N. Watari, et al. 